\title{
Potash Alum from Waste Aluminum Cans and Medicinal Foil
}

\author{
Dr.R.P.Ugwekar, G.P.Lakhawat , \\ Chemical Engg Deptt. , Priyadarshini Institute of Engineering \& Technology, Near CRPF Campus, Hingna \\ Road, Nagpur 440019, India, Mobile: 9423399290
}

\begin{abstract}
Modern beverage containers are usually composed of either aluminum in the form of aluminum cans, or polyethylene terephthalate (PETE).To produce single can the energy needed is about the same as that required keeping a 100-watt bulb light for 6 hours. That energy can be reduced by up to 95\% by recycling used aluminum cans. Medicinal aluminum foil is very thin sheet of rolled aluminum supplied in its pure form or in a variety of alloys \& tempers which give a wide choice of tensile properties. The thickness of foil ranges from the thinnest currently produces commercially at about $0.0065 \mathrm{~mm}$ to the defined upper limit of $0.2 \mathrm{~mm}$. Aluminum is easily recycled. Plain aluminum foil can be compacted \& remelted. Laminated aluminum is processed to separate the supporting layers \& the aluminum residue is reused in other applications. In addition, the energy contained in thin foil component of a laminate can be recovered in the form of heat. But the cans recycling process is time consuming process \& cost intensive. In this paper, instead of recycling aluminum into new metal cans, a chemical process will used to transform scrap aluminum into a useful chemical compound, potassium aluminum sulfate dodecahydrate $\left.\mathrm{KAl}_{(} \mathrm{SO}_{4}\right)_{2} .12 \mathrm{H}_{2} \mathrm{O}$, Commonly called "alum" will be described.
\end{abstract}

\section{INTRODUCTION}

Aluminium because of its low density, high tensile strength and resistance to corrosion is widely used for the manufacture of aeroplanes, automobiles lawn furniture as well as for aluminium cans. Being good conductor of electricity it is used for transmission of electricity. Aluminium is also used for making utensils. The recycling of aluminium cans and other aluminium products is a very positive contribution to saving our natural resources. Most of the recycled aluminium is melted and recast into other aluminium metal products or used in the production of various aluminium compounds, the most common of which are the alums. It is in the form of dry crystals. The Alum has wide application in industry such as textile industry, waste water treatment plant, paper \& pulp industry, food industry, etc.

The present demand of such compound is increase in every year as pollution in India increase tremendously. As the pollution is increasing, the need of pollution free environment is increase \& hence we use waste aluminum cans $\&$ medicinal aluminum foil which are also take part in polluting environment. This is our first step towards making environment pollution free. It gives moderate profit in low capital.

\section{Methods and materials:}

Empty aluminum beverage cans or medicinal aluminum foils are broken into small pieces. (Remove plastic coating over the cans before cut it into small pieces.) Weighed aluminum sample was taken in beaker \& $50 \mathrm{ml}$ of $1.4 \mathrm{M}$ solution of $\mathrm{KOH}$ was added. Beaker was kept on wire gauge \& heated so it is hot, but not boiling. Bubbles of hydrogen started coming from the reaction between aluminum \& aqueous $\mathrm{KOH}$. If the level of beaker drops to less than half of its original volume, distilled water was added to maintain level of liquid to its half. The reaction is completed when the hydrogen evolved ceases \& there are no visible pieces of aluminum metal. During the reaction, the initially colorless mixture was turned to dark grey \& black. If the plastic linings of cut sample were not completely removed it may be seen to be floating on the liquid. The dark material probably comes from the decomposition of plastic lining.

The material was filtered under vacuum. Be sure that the filter flask is securely clamped \& filter paper is moistened before you begin. The filtrate was a clear liquid with dark residue left on filter paper. Rinsing the beaker twice with $5 \mathrm{ml}$ portion of distilled water, pour each rinse through filter residue. When all of the liquid has passed through the filter paper, the vacuum was broken by disconnecting the filter paper from the filter flask. (Turn off the flow of liquid through steam-jet ejector only after vacuum has been broken.)

The clear filtrate was transferred into a clean beaker, cooled by, placing the beaker in a cooling bath of cold water. Slowly \& carefully, with stirring, $20 \mathrm{ml}$ of $9 \mathrm{M}$ solution of $\mathrm{H}_{2} \mathrm{SO}_{4}$ was added to the cooled solution. The solution get hot from the neutralization reaction occurring. It may noticed that the appearance of a white precipitate of aluminum hydroxide. (Addition of last few milliliters of the sulfuric acid will usually dissolve the $\mathrm{Al}(\mathrm{OH})_{3}$. If necessary, warm the solution gently,) while stirring, to completely dissolve any $\mathrm{Al}(\mathrm{OH})_{3}$ that might have formed. The final solution will contain potassium ions (from the $\mathrm{KOH}$ used), aluminum ion, \& 
sulfate ions. If, after a few minutes of heating, any solid residue remains, filter the mixture \& work with the clear filtrate. Reaction beaker was kept into the ice-water bath to chill.

Allowing the mixture to be chilled thoroughly for about 15 minutes, if crystals do not form, we may have to induce the crystallization. Stirring the solution rapidly, care should be taken not to splash any of the liquid from the beaker, or scratch the bottom of the beaker with stirring rod. As an alternative one or two very minute seed crystals may be added. Seed crystals (if desired) can be obtained by placing a drop of solution by boiling away some of the water $\&$ then cooling the solution in the ice bath. Clean $\&$ reassemble the vacuum filtration apparatus. Mix quantity of ethanol with same quantity of water in beaker Filter the alum crystal from the chilled solution, transferring as much of the crystalline product as possible to the funnel. Use half of the chilled ethanol solution to rinse the remaining crystals from the beaker into the funnel. Rinse the beaker again with the second half of solution. The crystals were distributed evenly on filter paper.

Allow the steam-jet ejector to pull air through crystals for few minutes. Remove alum from funnel with filter paper \& place it for drying. After drying the crystals were weighed. This is the lab process to manufacture alum from aluminum cans \& medicinal aluminum foil. This process can be commercialized by arranging the suitable assembly of equipments \& can achieve production of alum.

The overall reaction that takes place is as follows.

$2 \mathrm{Al}_{(\mathrm{s})}+2 \mathrm{KOH}_{(\mathrm{aq})}+4 \mathrm{H}_{2} \mathrm{SO}_{4(\mathrm{aq})}+22 \mathrm{H}_{2} \mathrm{O}_{(\mathrm{l})} \rightarrow 2 \mathrm{KAl}\left(\mathrm{SO}_{4}\right)_{2} \cdot 12 \mathrm{H}_{2} \mathrm{O}_{(\mathrm{s})}+3 \mathrm{H}_{2(\mathrm{~g})}$

The steps in the laboratory manufacturing process for Alum is given below

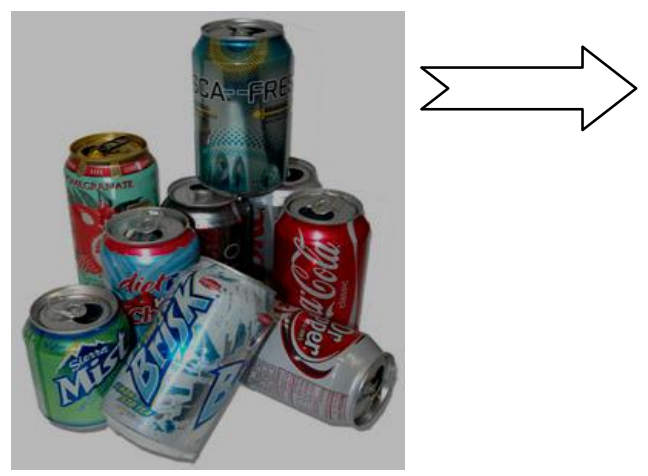

Fidi:Empty aluminum beverage cams

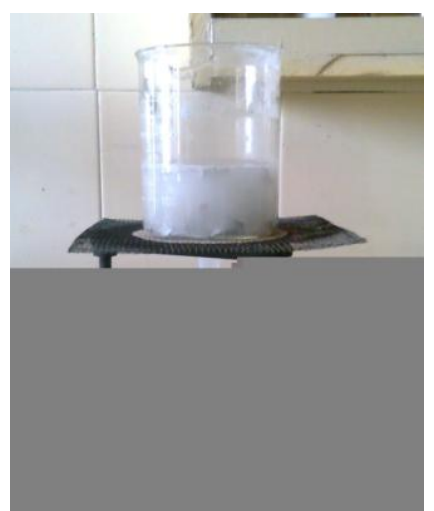

Fires Heating of sample solution

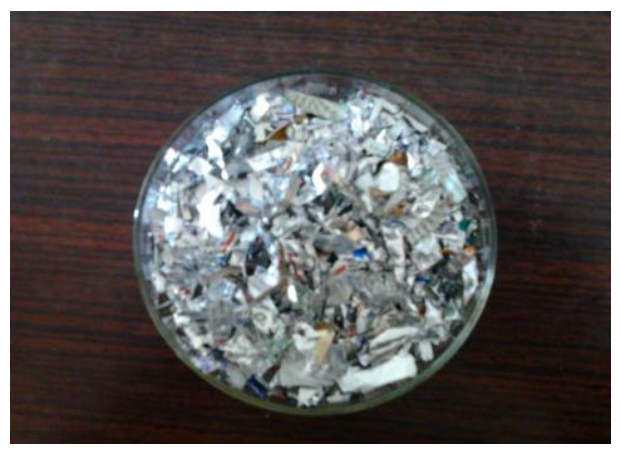

rige Cut aluminum sample

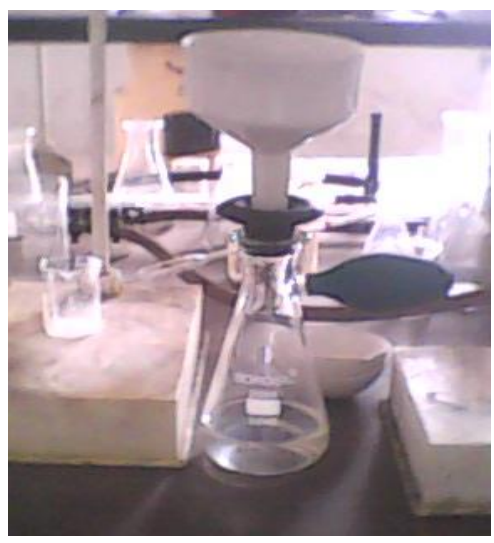

Fig4: V/acumm Filtuation Apparatus 


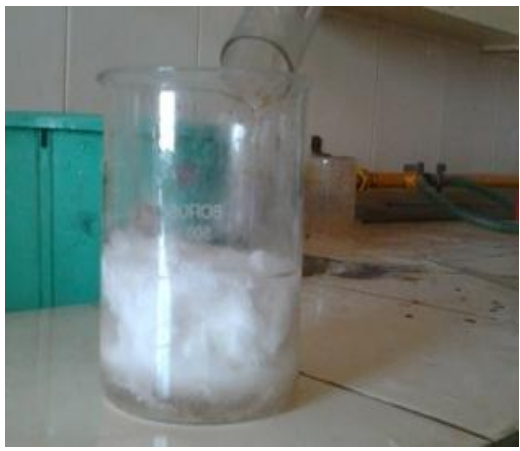

Fig 5: Slurry of alum

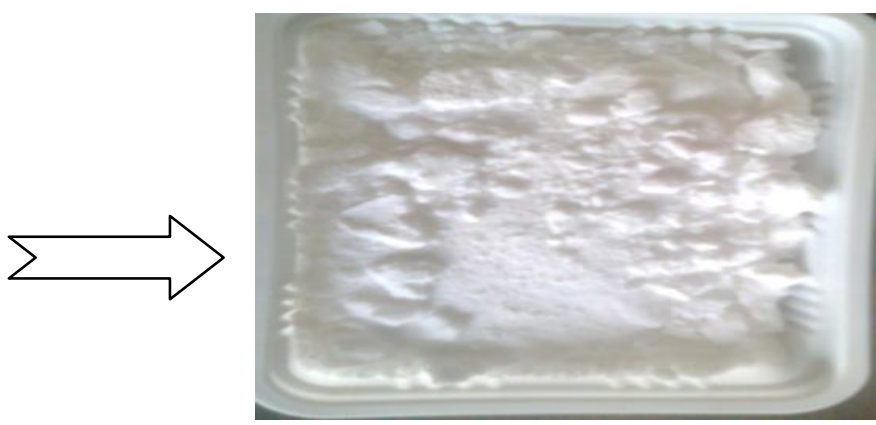

Fig 6: Alum

\section{Results \& Discussion}

The method was found to be suitable for using the waste material and turning it into the useful chemical. The environmental pollution due to metallic waste is increasing day by day. The alum is very useful chemical industrially and also on Domestic front. The alum got by this process is of best quality. The process can be integrated with the plant where lot of Aluminum scrap gets generated or as the use of aluminum cans for soft drinks are increasing the subsequent waste can be handled effectively by this process.

\section{CONCLUSION:}

Demand of alum increase with increased in awareness of purified water. Mineral water consumption has increased fourfold since the new millennium \& there is enough demand for alum at each city as there are many small scale mineral water packaging plants. Besides water purification market it has demand in industrial sector too. Paper industry is yet sector consuming alum. There is a little demand in fertilizer \& ceramic industries too.

It is an antiseptic \& astringent for this reason, it can be use as natural deodorant by inhibiting the growth of bacterial responsible for body odour \& hence it is widely uses in deodorants \& medicine includes ayurveda. Where it is called phitkari or saurashtri \& it is a traditional Chinese medicine. In Chinese it is called as Ming fan.It is also use as hardened for photographic emulation (film \& paper).There is no difficulty in making if the quantity is maintained to industrial standards

This technique is eco friendly, economic and profitable. This process can be applied in industries by suitable arrangement of assembly

\section{REFERENCES:}

[1] Dara S.S.," A textbook of Environmental chemistry and pollution control",S.Chand publication, page no 97-164 , 2000.

[2] Sharma .A , Shrama C , and Sharma A.K. Characteristics and management of Medical solid waste. Indian Journal of Environmental protection . 27(10):897-904 2007.

[3] Bailie et al. solid waste collection, transportation and processing. In:Environmental Engineers Handbook , vol III , 1974. ed B.G.Liptak, Chilton Book company, Radnor, Pennsylvania.

[4] Perry, R.H., "Perry's Chemical Engineering Handbook", $7^{\text {th }}$ ed McGraw Hill book company, page no.2-198,2-221,2-222 , 2001.

[5] CPCB, 2000. Status of solid waste generation, collection and disposal in metro cities. Central Urban pollution series: Cups/46/1999/2000 in 1999-2000. Center pollution control Board, New Delhi.

[6] David R. Lide. ," CRC handbook of chemistry and physics" eighty eight edition 2007-2008.Page no. 5-46,5-47,5-48.

[7] Kreith , F. 1994. Handbook of solid waste Management. McGraw-Hill Inc., New York.

[8] Maiti , S.K. Handbook of Methods in Environmental studies, vol 1. 2001. Water and wastewater Analysis. ABD Publishers, Jaipur. 